\title{
Ethnicity, Disadvantage and Other Variables in the Analysis of Birmingham Longitudinal School Attainment Datasets
}

Carl Parsons and Trevor Thompson, University of Greenwich

\begin{abstract}
Explaining and responding to inequalities in attainment are significant educational policy challenges in England as elsewhere. Data on five cohorts of Birmingham Local Education Authority (LEA) pupils, each approximately 13,000, were analysed by ethnicity, deprivation, gender and other relevant individual pupil variables. For the five successive cohorts of children, aged five in 1997 - 2001, analysis shows the attainment trajectory of each ethnic group from Baseline/Foundation Stage Profile (age 5) to GCSE (age 16). The relative constancy over time, the changes from one key stage to the next and the differences within broad ethnic categories argue against simplistic explanations. The ethnicity variable accounts for a relatively small amount of variance in pupil achievement.
\end{abstract}

Considering explanatory perspectives on educational inequalities and ethnicity in the light of these data, we conclude that a structuralist perspective offers the best explanation recognising economic exploitation, dominance and oppression at the national and local levels. Notions of institutional racism and Critical Race Theory (CRT) are inadequate and counter-productive in their inability to accommodate the range of attainment levels and educational experience of different ethnic groups. More tellingly, they lack causal explanations relevant to the UK and deflect attention from the need for sustained effort to reduce poverty and disadvantage as it affects children.

\section{Introduction}

In this paper we examine the complex relationship between ethnicity, disadvantage, gender and attainment. Against a background of national data, we analyse longitudinal data compiled by Birmingham local authority over nearly two decades. The ability to follow an age group through from Baseline/Foundation Stage Profile (FSP) to Key Stage 4 (age 16) has potential to illuminate current concerns about the attainment of different ethnic groups alongside other variables.

The research analyses attainment for four separate, consecutive cohorts (19972001) of children across five key assessment points (from 5 to 16 years of age) in Birmingham ${ }^{1}$. Children in the 1998 cohort were 5 years old in 1996/97 when assessed by what were called Baseline measures, and at Key Stage 4 were 16 yearolds in 2009. The 2001 cohort reached 16 in 2012. Scrutinising results of repeated measures on cohorts longitudinally helps to identify factors operating on pupils' progress as they pass through their school careers.

If there are ethnic differences in attainment, it is important to understand the nature of these differences. If differences in attainment are due to racist education processes, it is a teacher and school leadership issue. If the differences are attributable to national curriculum and assessment content and processes, then the educational establishment needs to consider such dimension. If differences in attainment are due to a failure to recognise and respond to class/socio-economic disadvantages, the solution lies in raising family income levels, better targeting of resources, and focussed interventions in schools and neighbourhoods. Similarly, the place of gender in recurrent attainment differences requires attention. It is important to know the relative contributions of ethnicity, socio-economic disadvantage and gender to guide efforts to remedy unjust inequalities. It is also 
important to know for which groups, where and at what stages of their education careers the inequalities emerge. A central line of argument is that variation of attainment in any one ethnic group at different stages in compulsory schooling has important implications for policy in the light of the Equalities and Human Rights Act (H M Government 2010) and the Public Sector Equality Duty (EHRC 2012b).

An earlier paper (Parsons 2016) focussed on attainment data in England at the different assessment points in terms of ethnicity, gender and deprivation, using annually published DfE 'snapshot' statistical first releases. This paper takes further the arguments about the role of these attributes as evidenced in Birmingham's longitudinal datasets and the trajectories of achievement of differently defined groups over time.

A note on the English legislative background is set out below, followed by the national picture, in terms of attainment inequalities, before detailing the Birmingham analyses. A final section seeks explanation of, and resistance to recognising and responding to longstanding inequalities with particular attention to multicultural and anti-racist education, institutional racism (Phillips 2011) critical race theory (CRT) (Gillborn 2006a; 2008b; Taylor, Gillborn and LadsonBillings 2009) and particular elements of David Gillborn's work, some of which was based on Birmingham data (Warren and Gillborn 2003).

\section{Post 2010 legislative and oversight background}

The Equalities Act (H M Government, 2010) set up the Equalities and Human Rights Commission which combined the roles of the Commission for Racial Equality with those of other equality and diversity organisations. It identified nine 'protected characteristics', two of which are ethnicity and gender. A public authority must, in the exercise of its functions, have due regard to the need to: 'eliminate discrimination, harassment, victimisation ... advance equality of opportunity ... foster good relations ....' (Section 149).

Poverty is not a 'protected characteristic', being regarded as a non-fixed personal attribute. The public sector duty regarding socio-economic inequalities requires, 'An authority ... when making decisions of a strategic nature ... have due regard to the desirability of exercising them in a way that is designed to reduce the inequalities of outcome which result from socio-economic disadvantage' (H M Government 2010: Part 1 (1)).

Guidance and exhortation continue (EHRC 2012a). Funding was made available for anti-poverty measures through the Pupil Premium Grant from 2011 and stiff, public targets set to reduce the gaps in attainment between Free School Meals (FSM) and non-FSM children. The 'ethnicity gap' was never widely publicised and never a basis for target setting with regard to low attaining ethnic groups.

The EHRC (2016) five year report lists many enduring concerns related to university degree class, employment prospects, health, exclusions related to ethnicity as well as noting the low educational performance of free school meals (FSM) children designated as White.

\section{Attainment inequalities at the national level}

\section{Ethnicity}

In 2013, there were 6,679,800 pupils in schools in England. Of these, 78\% are White, 73\% defined more narrowly as White British. There were 354,000 pupils 
(5.3\%) nationally in one of the three Black categories and 651,000 defined as Asian $(9.8 \%)$.

Table 1. National GCSE results by gender and FSM eligibility 2013

\begin{tabular}{|c|c|c|c|c|c|c|c|c|c|c|}
\hline & \multicolumn{4}{|c|}{$\begin{array}{l}\text { Percentage achieving } \\
5+A^{*}-C \text { GCSEs inc } \\
\text { English \& mathematics } \\
\text { - FSM }\end{array}$} & \multicolumn{4}{|c|}{$\begin{array}{l}\text { Percentage achieving } \\
5+A^{*}-C \text { GCSEs inc. } \\
\text { English \& mathematics } \\
\text { - Non-FSM }\end{array}$} & \multirow[b]{2}{*}{\begin{tabular}{|l} 
Total \\
Pupils
\end{tabular}} & \multirow[b]{2}{*}{$\begin{array}{l}\text { Total } 5+A^{*}-C \\
\text { GCSEs inc. } \\
\text { E \& M }\end{array}$} \\
\hline & \begin{tabular}{|c|} 
Number \\
FSM \\
pupils \\
\end{tabular} & Boys & Girls & $\begin{array}{l}\text { Total } \\
\text { FSM }\end{array}$ & $\begin{array}{r}\text { Number } \\
\text { non-FSM } \\
\text { pupils }\end{array}$ & Boys & Girls & $\begin{array}{l}\text { Total } \\
\text { Non- } \\
\text { FSM }\end{array}$ & & \\
\hline White & 58,420 & 28.4 & 37.1 & 32.7 & 402,125 & 59.2 & 69.5 & 64.2 & 460,545 & 60.2 \\
\hline White British & 54,890 & 27.9 & 36.8 & 32.3 & 383,440 & 59.4 & 69.9 & 64.6 & 438,330 & 60.5 \\
\hline Irish & 287 & 38.9 & 39.2 & 39.0 & 1,610 & 69.8 & 79.2 & 74.3 & 1,897 & 69.0 \\
\hline Traveller of Irish heritage & 85 & 11.9 & 14.0 & 12.9 & 52 & 14.8 & 36.0 & 25.0 & 137 & 17.5 \\
\hline Gypsy / Roma & 385 & 10.2 & 8.6 & 9.4 & 423 & 13.8 & 22.4 & 18.4 & 808 & 14.1 \\
\hline Other White background & 2,773 & 38.9 & 48.4 & 43.6 & 16,600 & 53.2 & 62.0 & 57.5 & 19,373 & 55.5 \\
\hline Mixed & 4,555 & 39.7 & 48.3 & 44.0 & 17,045 & 62.8 & 72.3 & 67.6 & 21,600 & 62.6 \\
\hline White \& Black Caribbean & 1,828 & 34.8 & 40.4 & 37.6 & 5,500 & 54.8 & 66.3 & 60.7 & 7,328 & 54.9 \\
\hline White \& Black African & 537 & 44.2 & 52.4 & 48.6 & 1,793 & 61.4 & 74.2 & 67.7 & 2,330 & 63.3 \\
\hline White \& Asian & 706 & 38.6 & 57.7 & 47.9 & 3,728 & 70.5 & 77.2 & 73.8 & 4,434 & 69.7 \\
\hline Other mixed background & 1,484 & 44.6 & 52.2 & 48.3 & 6,024 & 65.3 & 74.4 & 69.9 & 7,508 & 65.6 \\
\hline Asian & 10,451 & 48.6 & 57.1 & 52.8 & 36,334 & 62.4 & 72.9 & 67.5 & 46,785 & 64.2 \\
\hline Indian & 1,308 & 56.7 & 66.6 & 61.4 & 12,237 & 72.0 & 82.7 & 77.2 & 13,545 & 75.7 \\
\hline Pakistani & 4,973 & 42.9 & 51.1 & 46.8 & 12,806 & 54.1 & 63.8 & 58.8 & 17,779 & 55.5 \\
\hline Bangladeshi & 2,958 & 55.5 & 62.8 & 59.2 & 4,723 & 62.3 & 71.7 & 67.0 & 7,681 & 64.0 \\
\hline Other Asian background & 1,212 & 47.8 & 56.9 & 52.4 & 6,568 & 60.9 & 72.6 & 66.6 & 7,780 & 64.4 \\
\hline Black & 8,424 & 43.1 & 53.3 & 48.2 & 19,023 & 57.2 & 67.8 & 62.5 & 27,447 & 58.1 \\
\hline Black Caribbean & 2,061 & 36.9 & 47.7 & 42.1 & 6,099 & 50.4 & 63.4 & 57.0 & 8,160 & 53.3 \\
\hline Black African & 5,440 & 46.6 & 56.0 & 51.4 & 10,761 & 61.5 & 70.9 & 66.2 & 16,201 & 61.2 \\
\hline Other Black background & 923 & 37.5 & 48.9 & 43.1 & 2,163 & 54.8 & 64.6 & 59.6 & 3,086 & 54.7 \\
\hline Chinese & 168 & 74.1 & 79.5 & 76.8 & 2,087 & 74.3 & 82.5 & 78.3 & 2,255 & 78.2 \\
\hline Other ethnic group & 2,262 & 46.4 & 56.8 & 51.5 & 4,978 & 59.3 & 66.7 & 62.8 & 7,240 & 59.2 \\
\hline Totals & 85,185 & 33.5 & 42.5 & $\underline{37.9}$ & 486,137 & 59.5 & 69.8 & $\underline{64.6}$ & 571,322 & 60.6 \\
\hline
\end{tabular}

DfE 2015b Extracted from Table 2a. Shaded numbers indicate low attainment relative to the Total FSM or Total Non-FSM percentages (5 percentage points below total mean).

For most minority ethnic groups, there have been year on year improvements in attainment by 2013. As shown in Table 1, Chinese, Black African, Indian, Bangladeshi, mixed White and Asian, mixed White and Black African and other Asian background pupils register mean attainment scores at age 16 above the national average. Black Caribbean, Other Black background and Mixed White Black Caribbean pupils have average attainment scores below the national average but Traveller and Gypsy/Roma children have the lowest mean attainment scores; all these are highlighted in the final column. Pakistani pupils achieve better and better as they progress through the school system but remain below the national average at Key Stage 4 in 2013 and in 2015 figures. This is the relatively constant picture over the past decade with distinctive changes between 2008 and 2015 being the Black African, mixed White/Black African and Bangladeshi pupils for whom the mean attainment at 16 has risen to above the national average. The sizes of the 
populations, the attainment levels and the changes over time nationally are relevant to the discussions of the longitudinal Birmingham data.

\section{Gender}

At the Foundation Stage Profile (aged 4+) stage, for the years 2008 to 2014, girls are 17 percentage points ahead of boys (DfE 2015a, Table 1). This difference remains large up to Key Stage 4 (DfE 2015b). Table 1 shows that approximately $10 \%$ more girls than boys attain $5 \mathrm{~A}^{*}$-C subjects including mathematics and English. This applies for every ethnic group, whether entitled to free school meals (FSM) or not, except for the small numbers FSM Irish, Travellers and Gypsy/Roma. However, the usual ratio is reasserted for non-FSM pupils in these groups.

\section{Deprivation}

The average attainment of FSM pupils (17\% of the school population nationally) is around 20 points lower than that of non-FSM children at each national assessment point. As can be seen from Table 1, while there is some variation and some smaller differences in the Asian category. FSM girls and FSM boys are both way below their non-FSM counterparts.

Pupils living in the 10 poorest areas of England, as indicated by the Income Deprivation Affecting Children Index (IDACI), have the lowest attainment levels; the poorest decile achieves an average of $44 \% 5 A^{*}$-C GCSE grades including mathematics and English, 32 lower than those in the top decile (DfE 2015b, Table A1) a difference which was no smaller in the previous four years. FSM pupils constitute a group larger in number than any single ethnic minority group.

Age

Autumn born children do better at the earliest stages although the advantage reduces as children get older, but nevertheless remains significant at 16 .

Interaction between factors

Gender within ethnic groups is significant. Poverty and gender (being male) together with ethnicity (being Black Caribbean or Mixed White and Black Caribbean) have a particularly strong association with low attainment. White FSM boys and girls have the lowest mean scores compared with any other gender/ethnic group at KS4 (DfE 2015b, Table 2a).

\section{Examining inequalities using longitudinal data from one local authority}

The aim of the study was to examine the relationships between ethnicity, gender, socio-economic disadvantage and attainment within one large education authority through the analysis of five longitudinal cohorts of children. We specifically sought to analyse:

1. recurrent patterns of attainment from age 5 to 16 for the four Birmingham cohorts;

2. differing achievement levels within the categories of Black and Mixed heritage;

3. the apparent advantage deriving from being a girl, being non-FSM, being White as compared with Black;

4. the gender difference in attainment within ethnic categories and by FSM status; 
5. the relative effects of ethnicity, gender, deprivation, special educational needs(SEN) and age on attainment at different key stage levels, using multiple regression procedures.

The final section addresses theoretical perspectives and causal factors which claim to explain attainment differences and the barriers to achieving greater equity.

\section{Methods}

The data were supplied by Birmingham LEA as Excel files. For each of the four cohorts there was a continuous record of pupils with background variables and attainment scores from the Baseline measure or Foundation Stage Profile (as it became for the 2000 and 2001 cohorts), through all four subsequent assessment key stages. The data were anonymised in terms of pupil and school names before receipt from Birmingham.

The data supplied included date of birth, postcode, gender, ethnicity - according to the full DFE coding, FSM and SEN status. The ethnicity data are set out in Table 2 with national comparisons.

Ethnicity in the analyses was coded as two variables, one of which aggregates the three Black groups as BLACK and the four Mixed groups as one (Table 3) while the second presents data with both Black and Mixed groups broken down into their constituent subgroups (Figures 5, 6 and $10-12$ ).

Table 2. Totals by ethnicity in the Birmingham four school population cohorts and national comparisons for 2013

\begin{tabular}{|c|c|c|c|c|c|c|c|c|}
\hline Ethnicity & 1998 & 1999 & 2000 & 2001 & $\begin{array}{l}\text { Birminghar } \\
\text { Total pupil } \\
\text { numbers }\end{array}$ & m 2013 & $\begin{array}{l}\text { National } \\
\text { Total pupil } \\
\text { numbers }\end{array}$ & $\begin{array}{l}2013 \\
1 \quad \%\end{array}$ \\
\hline Black African & 83 & 174 & 68 & 324 & 9,058 & $5.7 \%$ & 219,825 & $3.3 \%$ \\
\hline Black Caribbean & 617 & 716 & 536 & 685 & 7,569 & $4.8 \%$ & 89,410 & $1.3 \%$ \\
\hline Any Other Black Background & 107 & 92 & 90 & 120 & 1,800 & $1.1 \%$ & 42,325 & $0.6 \%$ \\
\hline Pakistani & 2273 & 2546 & 2248 & 2647 & 38,915 & $24.7 \%$ & 261,930 & $4.0 \%$ \\
\hline Bangladeshi & 440 & 563 & 462 & 593 & 8,691 & $5.5 \%$ & 107,055 & $1.6 \%$ \\
\hline Indian & 699 & 728 & 609 & 667 & 8,801 & $5.6 \%$ & 174,800 & $2.6 \%$ \\
\hline Mixed White \& Asian & 111 & 114 & 124 & 144 & 2,321 & $1.5 \%$ & 68,385 & $1.0 \%$ \\
\hline Mixed White \& Black African & 48 & 43 & 53 & 47 & 648 & $0.4 \%$ & 36,505 & $0.6 \%$ \\
\hline Mixed White \& Black Caribbean & 367 & 355 & 483 & 387 & 5,084 & $3.2 \%$ & 91,610 & $1.4 \%$ \\
\hline Any Other Mixed Background & 253 & 241 & 195 & 228 & 3,180 & $2.0 \%$ & 108,415 & $1.6 \%$ \\
\hline White & 6144 & 6522 & 5487 & 5784 & 61,310 & $38.9 \%$ & $5,183,985$ & $78.4 \%$ \\
\hline Other, unclassified or missing & 1290 & 863 & 342 & 883 & 21,731 & $13.8 \%$ & 494,900 & $2.4 \%$ \\
\hline TOTAL & 12432 & 12957 & 10697 & 12509 & 157,670 & & $6,678,395$ & \\
\hline Minority Ethnic Pupils & $44.9 \%$ & $46.1 \%$ & $47.0 \%$ & $50.2 \%$ & & $63.3 \%$ & & $26.4 \%$ \\
\hline
\end{tabular}

Source: Birmingham data and DfE 2013, Local authority and regional tables: 9a, b, c. 
The key to the 12 ethnicity labels in figures in this article is set out below.

Table 3. Key for the 12 ethnicity groups

\begin{tabular}{|c|c|c|}
\hline Aggregate group & $\begin{array}{l}\text { Disaggregate } \\
\text { group label }\end{array}$ & Description \\
\hline \multirow{3}{*}{ BLACK } & BAFR & Black African \\
\hline & BCRB & Black Caribbean \\
\hline & BOTH & Any Other Black background \\
\hline \multirow{4}{*}{ MIXED } & MWBC & Mixed White and Black Caribbean \\
\hline & MWBA & Mixed White and Black African \\
\hline & MWAS & Mixed White and Asian \\
\hline & MOTH & Any Other Mixed background \\
\hline IND & IND & Indian \\
\hline PAK & PAK & Pakistani \\
\hline BANG & BANG & Bangladeshi \\
\hline \multirow[t]{2}{*}{$\begin{array}{l}\text { WHITE inc Irish, Travellers } \\
\text { and Other White }\end{array}$} & WBRI & White British \\
\hline & OTHER & $\begin{array}{l}\text { Including Chinese, other Asian, other } \\
\text { White and unclassified }\end{array}$ \\
\hline
\end{tabular}

Attainment data allowed single scores at each key stage to be calculated for each pupil, the Average Point Score (APS for Key Stages 1 to 3) and the Total Point Score at Key Stage 4. For some pupils there was only one assessment on record or only for Baseline/FSP and KS1, presumably because their families were transient. They were removed from the analysis (over 1,000 cases per cohort). The reduced population for which most of the relevant assessment data were present is indicated in Table 4 below. The numbers subjected to analysis at each key stage are shown and the much reduced number for which all attainment data were present is given in the last column. A compromise was made in including pupils even when all attainment data was not given, even though our interest was in longitudinal cohort progression. This decision made little difference in the calculated means and the bias resulting was judged to be unremarkable.

The attainment data for each of the four cohorts, each numbering about 12,000 (except the 2000 cohort - see explanation below Table 4), were analysed separately using SPSS. The five KS attainments had different means and different spreads about the mean. To make the magnitude of any group differences more easily comparable across all assessments, scores were transformed into standardized form for each key stage assessment points. Standardising assessment scores sets the mean at zero and the standard deviation at 1. 
Table 4. Numbers of pupils in each Birmingham cohort at each assessment point

\begin{tabular}{|c|c|c|c|c|c|c|c|c|}
\hline $\begin{array}{l}\text { Year in } \\
\text { which } \\
\text { cohort } \\
\text { were in } \\
\text { Reception } \\
\text { (ie aged 5) }\end{array}$ & $\begin{array}{l}\text { Original } \\
\text { cohort } \\
\text { size }\end{array}$ & $\begin{array}{l}\text { Reduced } \\
\text { cohort } \\
\text { size }\end{array}$ & $\begin{array}{l}\text { Baseline/ } \\
\text { Foundation } \\
\text { Stage Profile } \\
\text { (FSP)* }\end{array}$ & $\begin{array}{l}\text { Key } \\
\text { Stage 1 } \\
\text { Average } \\
\text { Points } \\
\text { Score }\end{array}$ & $\begin{array}{l}\text { Key } \\
\text { Stage } 2 \\
\text { Average } \\
\text { Points } \\
\text { Score }\end{array}$ & $\begin{array}{l}\text { Key } \\
\text { Stage } 3 \\
\text { Average } \\
\text { Points } \\
\text { Score }\end{array}$ & $\begin{array}{l}\text { Key } \\
\text { Stage } 4 \\
\text { (Total } \\
\text { Points } \\
\text { Score) }\end{array}$ & $\begin{array}{l}\text { Number } \\
\text { for whom } \\
\text { all } \\
\text { attainment } \\
\text { data } \\
\text { present }\end{array}$ \\
\hline 1998 & 13711 & 12432 & 9868 & 12329 & 12067 & 10013 & 9742 & 7382 \\
\hline 1999 & 13437 & 12957 & 11397 & 12849 & 12055 & 9824 & 11972 & 8258 \\
\hline $2000^{* *}$ & 11436 & 10697 & 10697 & 10697 & 10490 & 8915 & 8283 & 8084 \\
\hline 2001 & 13753 & 12509 & 10928 & 12025 & 12043 & 9519 & 9707 & 7455 \\
\hline
\end{tabular}

${ }^{*}$ The FSP replaced the Baseline measure in $2000 .{ }^{* *}$ It appears that the 2000 cohort was only maintained from KS 1 onwards if FSP data were present.

The local context

Birmingham Local Authority is the third largest in England in terms of pupil numbers. As shown in Table 3, nationally $26 \%$ were ethnic minority in 2013 . The proportion of Birmingham pupils categorised as ethnic minority was $63 \%$.

Birmingham has a larger number of ethnic minority pupils (DfE 2013) than any other local authority in England at 99,600. Pakistani pupils form nearly 25\% of the total and Bangladeshi, Indian, Black Caribbean and Black African each form about $5 \%$.

In terms of the proportion for whom English is not the first language, Birmingham has 40\%. Outside London, only Slough, Luton and Leicester have higher percentages of ethnic minority pupils (DfE 2013, Tables 10a-10d).

Department for Education data (DfE 2013) show that Birmingham has, at 31.4\%, almost double the national percentage of children from poor backgrounds (FSM entitlement). This applies to every ethnic minority group. Examining national and Birmingham data on national attainment levels at 16 for pupils by FSM eligibility from 2008 to 2015 reveals both FSM and non-FSM groups in Birmingham have higher proportions achieving $5 A^{*}$-C GCSEs including English and mathematics than the comparable national means; perversely, the Birmingham cohorts in total are shown as performing below the national mean (DfE 2014: Table 5; DfE 2016: Table LA8). This is because the proportion of Birmingham KS 4 pupils who were FSM is more than double the national figure (Table 6); despite $51 \%$ of these achieving 5 $\mathrm{A}^{*}-\mathrm{C}$ including English and mathematics (10\% more than the national average), it reduces the overall average, when combined with the non-FSM results percentage, to a little below the national figure of $65.8 \%$. The gap between FSM and non-FSM pupil attainment at KS 4 has also been consistently smaller than the gap nationally. 
Table 5. Birmingham 1999 cohort by IDACI Quintile

\begin{tabular}{cccc}
\hline 1999 Quintile & $\begin{array}{l}\text { Number of } \\
\text { addresses }\end{array}$ & $\begin{array}{l}\text { Birmingham } \\
\text { Percentage }\end{array}$ & $\begin{array}{l}\text { National } \\
\text { Percentage }\end{array}$ \\
\hline 1 (most deprived) & 7873 & 62.0 & 20 \\
\hline 2 & 1849 & 14.6 & 20 \\
\hline 3 & 1605 & 12.6 & 20 \\
\hline 4 & 823 & 6.5 & 20 \\
\hline 5 (least deprived) & 548 & 4.3 & 20 \\
\hline Total cohort size & 12,698 & & \\
\hline Eligible for FSM 2013 GCSE entries & 32.5 & 14.4 \\
\hline
\end{tabular}

The Income Deprivation Affecting Children Index (IDACI) in England divides the population into 32,000 super output areas of roughly equal size groups ranked by affluence/deprivation. Table 5 shows that in Birmingham's school population, as judged from the 1999 cohort, over $60 \%$ live in areas judged to be amongst the poorest 20\% in England. This cohort is chosen as the comparison group because these would be 16 year-olds in 2010, the date to which the national IDACI data applies. 
Table 6. Pearson correlation coefficients Birmingham1999 cohort

\begin{tabular}{|c|c|c|c|c|c|c|c|c|c|}
\hline & KS1 & KS2 & KS3 & KS4 & Age & $\begin{array}{l}F S M \\
Y=1 \\
N=2\end{array}$ & $\begin{array}{l}\text { SEN } \\
\mathrm{Y}=1 \\
\mathrm{~N}=2 \\
\end{array}$ & $\begin{array}{l}\text { GENDER } \\
\mathrm{M}=1 \\
\mathrm{~F}=2\end{array}$ & $\begin{array}{l}\text { IDACI } \\
\text { Score } \\
\end{array}$ \\
\hline FSP & $.57^{* *}$ & $.49 * *$ & $.48^{* *}$ & $.26^{* *}$ & $.24^{* *}$ & $.22^{* *}$ & $.28^{* *}$ & $.11^{* *}$ & $-.20 * *$ \\
\hline KS1 & & $.79^{* *}$ & $.76^{* *}$ & $.43^{* *}$ & $.15^{* *}$ & $.27^{* *}$ & $.31^{* *}$ & $.11^{* *}$ & $-.24^{* *}$ \\
\hline KS2 & & & $.85^{* *}$ & $.48^{* *}$ & $.07^{* *}$ & $.26^{* *}$ & $.29^{* *}$ & $.05^{* *}$ & $-.23^{* *}$ \\
\hline KS3 & & & & $.60^{* *}$ & $.05^{* *}$ & $.28^{* *}$ & $.29^{* *}$ & $.09^{* *}$ & $-.27^{* *}$ \\
\hline KS4 & & & & & $.03^{* *}$ & $.19^{* *}$ & $.16^{* *}$ & $.14^{* *}$ & $-.14^{* *}$ \\
\hline Age & & & & & & $.02 *$ & $-.08^{* *}$ & .00 & $-.02^{*}$ \\
\hline FSM & & & & & & & $.11^{* *}$ & -.01 & $-.36^{* *}$ \\
\hline SEN & & & & & & & & $.08^{* *}$ & $-.09 * *$ \\
\hline GENDER & & & & & & & & & .00 \\
\hline
\end{tabular}

** Correlation is significant at the 0.01 level 2-tailed)

Key: FSM= Free School Meal entitlement (at any time); SEN= Special Educational Needs (at any time); IDACl= Income Deprivation Affecting Children Index.

Table 6 shows the simple Pearson correlation coefficients for the 1999 cohort, between the average attainment measures at the five assessment points and a range of variables available that one might hypothesise are related to the attainment levels, without including ethnicity. These variables are: age, free school meals entitlement, special needs (any level), gender and IDACI of the pupil's postcode. The same analysis for the 1997, 1998, 2000 and 2001 cohorts shows very similar correlations. Higher mean scores on KS assessments are achieved by those with no FSMs, without special needs, females and those living in more affluent areas.

The strongest correlations are from one assessment point to the next. The correlation between assessed ability at five years of age (Baseline in this cohort) and overall attainment at KS4 (the end of compulsory schooling) is as high as 0.26. The moderate correlations (.2+) between FSM, SEN and IDACI with FSP to KS3 attainment scores fall (.14) for KS4.

In terms of personal characteristics, Age correlates less at each successive key stage assessment point, while gender decreases as a correlate until Key Stage 4, at which point it increases. 


\section{The annually recurrent pattern of attainment from age 5 to 16 for the four Birmingham cohorts}

The mean attainment levels of six primary ethnic categories at each key stage for each of the four cohorts are set out in figures 1 to 4 . A standardized attainment score of zero represents the local authority mean attainment. These figures demonstrate the remarkable stability in attainment levels across the four cohorts. In each ethnic group, attainment follows a very similar trajectory over the five assessment points within each separate cohort.

Amongst the Asian heritage pupils, Indian children start at the Baseline or Foundation Stage Profile level at around average and achieve at increasingly higher levels ${ }^{2}$. Bangladeshi and Pakistani pupils start at a very low level, compared to the other ethnic groups, but improve steadily throughout their schooling. Bangladeshi pupils score above the Birmingham average at KS4.

Of concern are White, Black and Mixed populations which show decline by comparison with the local authority mean. The Black and Mixed groups will be disaggregated later as it is recognised that those with a Caribbean heritage have, with great regularity, been recorded as scoring lower. The score of these three groups fall from one key stage to the next, with the Black group recovering slightly at $\mathrm{KS}^{3}$.

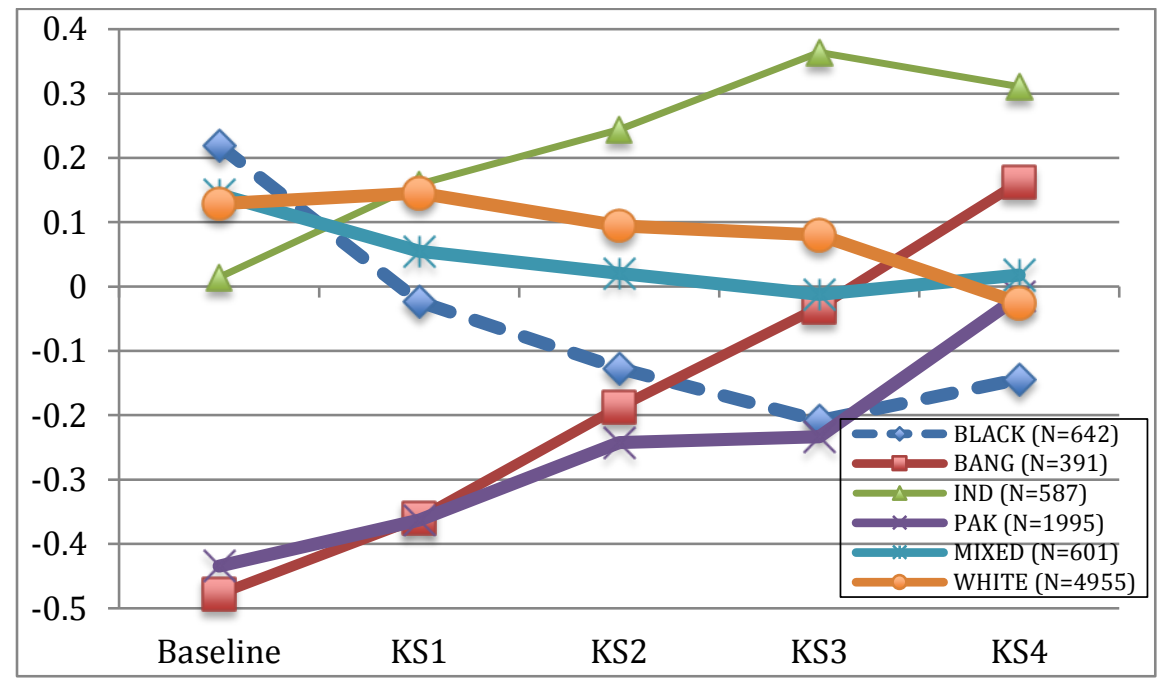

Figure 1. Relative mean ethnic group scores (standardized) at five assessment points for the Birmingham 1998 cohort 


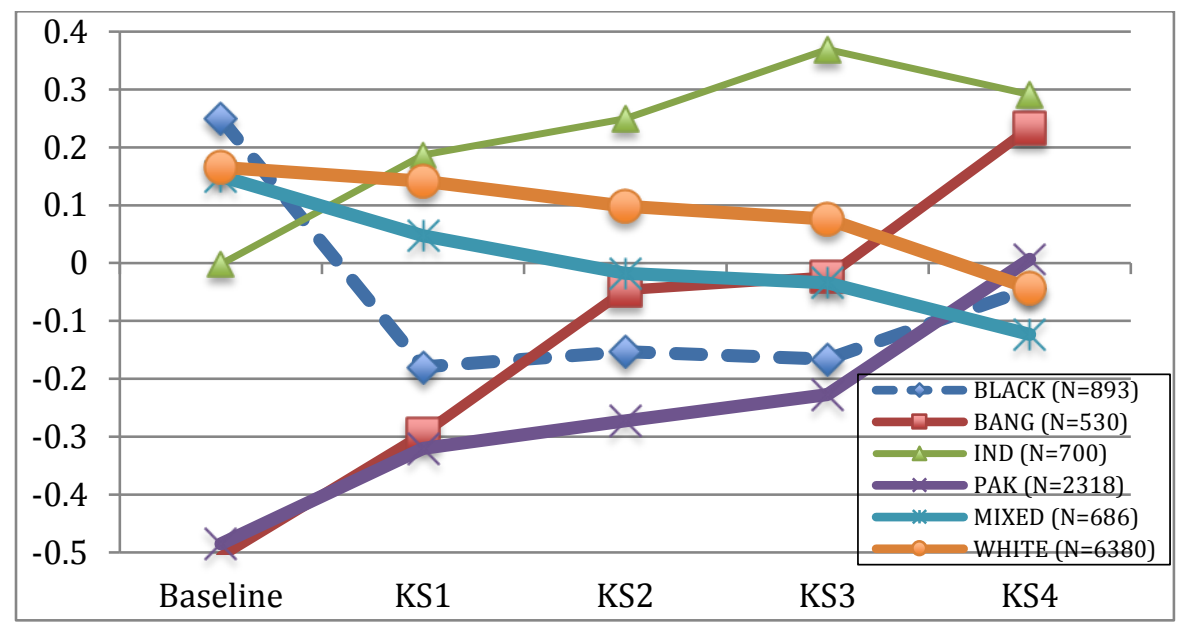

Figure 2. Relative mean ethnic group scores (standardized) at five assessment points for the Birmingham 1999 cohort

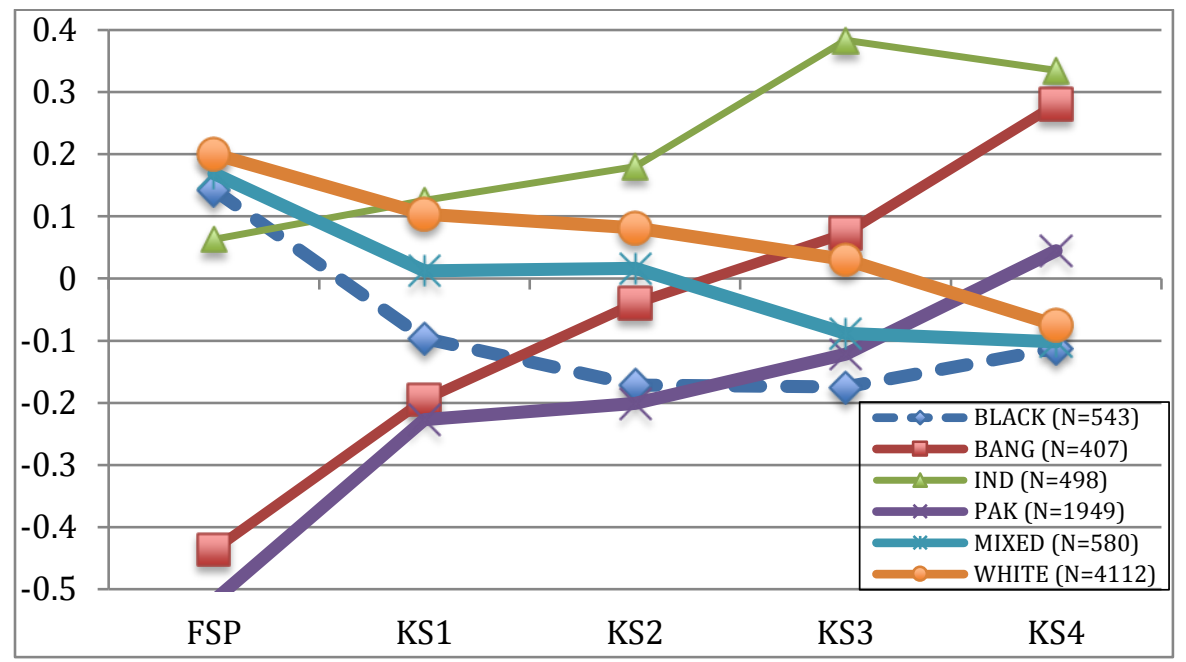

Figure 3. Relative mean ethnic group scores (standardized) at five assessment points for the Birmingham 2000 cohort

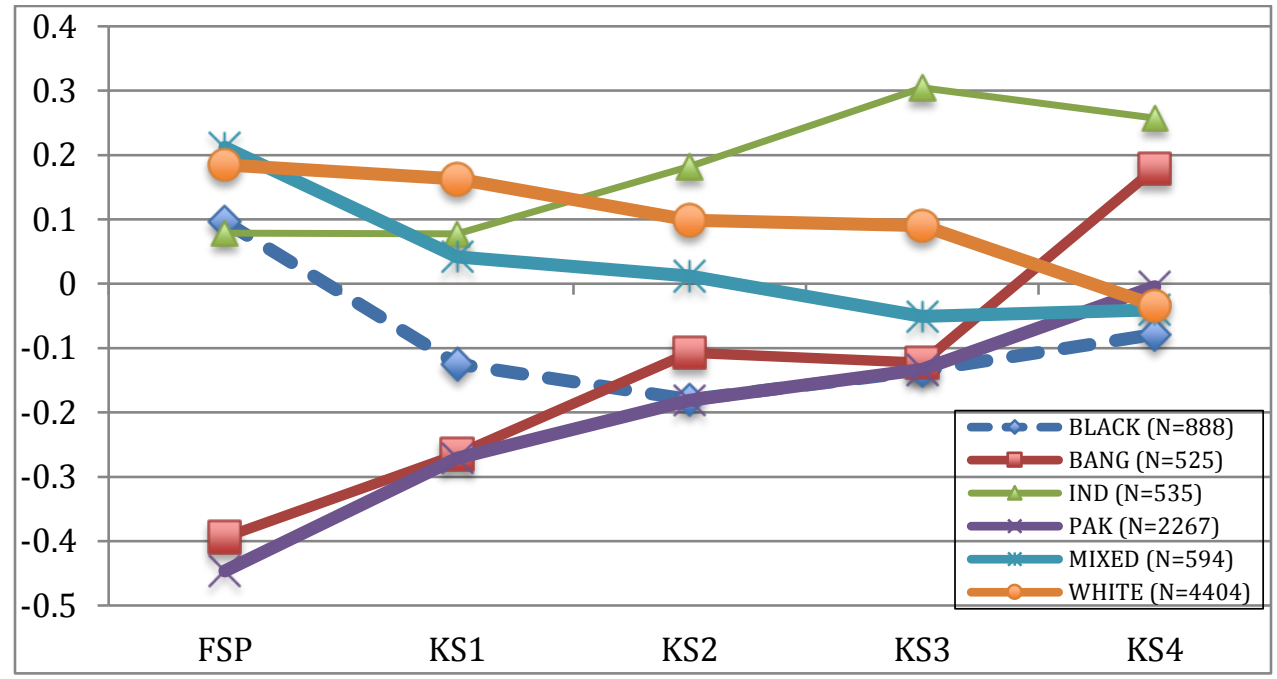

Figure 4. Relative mean ethnic group scores (standardized) at five assessment points for the Birmingham 2001 cohort 
The changed assessment protocol, from Baseline to Foundation Stage Profile, operating in 2000 and 2001 (Figures 3 \& 4), clearly brings about mean levels of assessed ability in the BLACK group which are then lower than the mean for the WHITE and the MIXED groups compared with years 1997 to 1999 (Figures 1 to 3). But this does not alter the subsequent trajectory of attainment, despite David Gillborn's (2008a; 2008b) 'conspiracy' claims that the FSP assessment was introduced because BLACK children were outperforming WHITE children on the simpler Baseline assessment.

On the evidence of the endurance of these trajectories, there is something about the content and processes of the English educational system that evidently suits very well pupils of Asian and Indian heritage and, as they go up the age range, those with Pakistani and Bangladeshi heritages. Home language and increasing competence acquired by Asian children as they move through the school are obviously a factor. Some pupils identified with Black and or Mixed backgrounds do less well. This is demonstrated in the next section.

\section{Differing achievement levels within the categories of Black and Mixed heritage}

Further breakdown of the Black and Mixed heritage ethnic categories (see Table 2), in recognition of known different outcomes for each, reveals a more complex but nonetheless largely stable picture. Figures 6 and 7 present the mean standardized scores for the 1998 and 2000 cohorts. The sizes of these sub-populations are given in brackets beside the ethnicity code and three groups have quite small numbers within the Birmingham population. It is worth emphasising, however, that we are dealing with whole population figures, not a sample, and the small numbers are simply the reality.

Mean standardized attainment scores for White pupils begin high and decline at almost every point as they move through the key stages. Black Caribbean (BCRB) pupils fall from a relatively high mean score through to KS3 and then rising, with those designated Black Other (BOTH) following a similar trajectory. Mixed White/Black Caribbean (MWBC) and Black Other pupils have similarly low attainment levels at KS4. Black Africans (BAFR) and Mixed White and Black Africans (MWBA) show big fluctuations but numbers are small; both groups rise to perform very well at KS4 in the years shown, rising above the mean for White pupils. The relative attainment levels are fairly close to those found with the national data. 


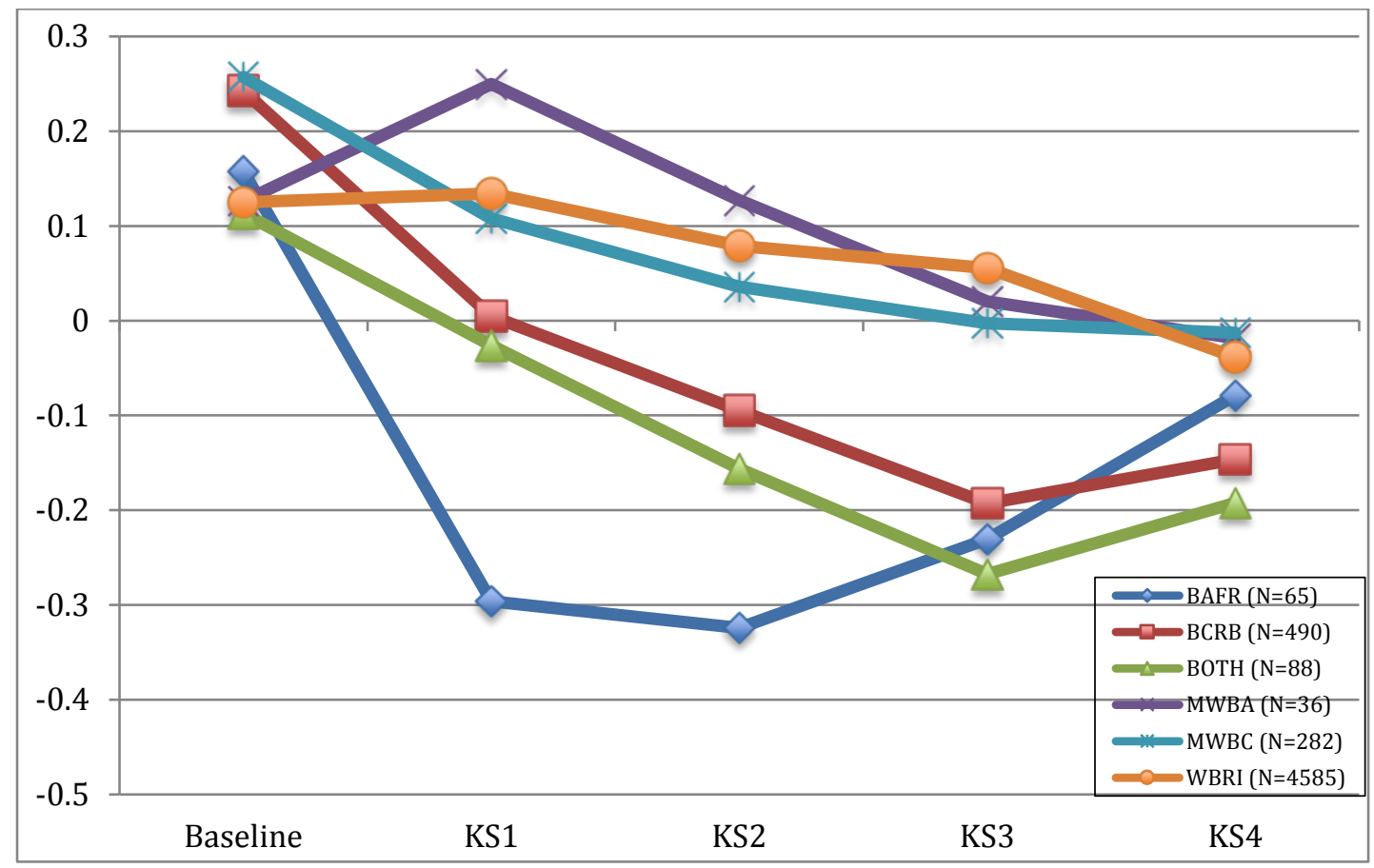

Figure 5. Standardized attainment scores for the Birmingham 1998 cohort for Black and Mixed subgroups (see Table 2 for ethnic group key)

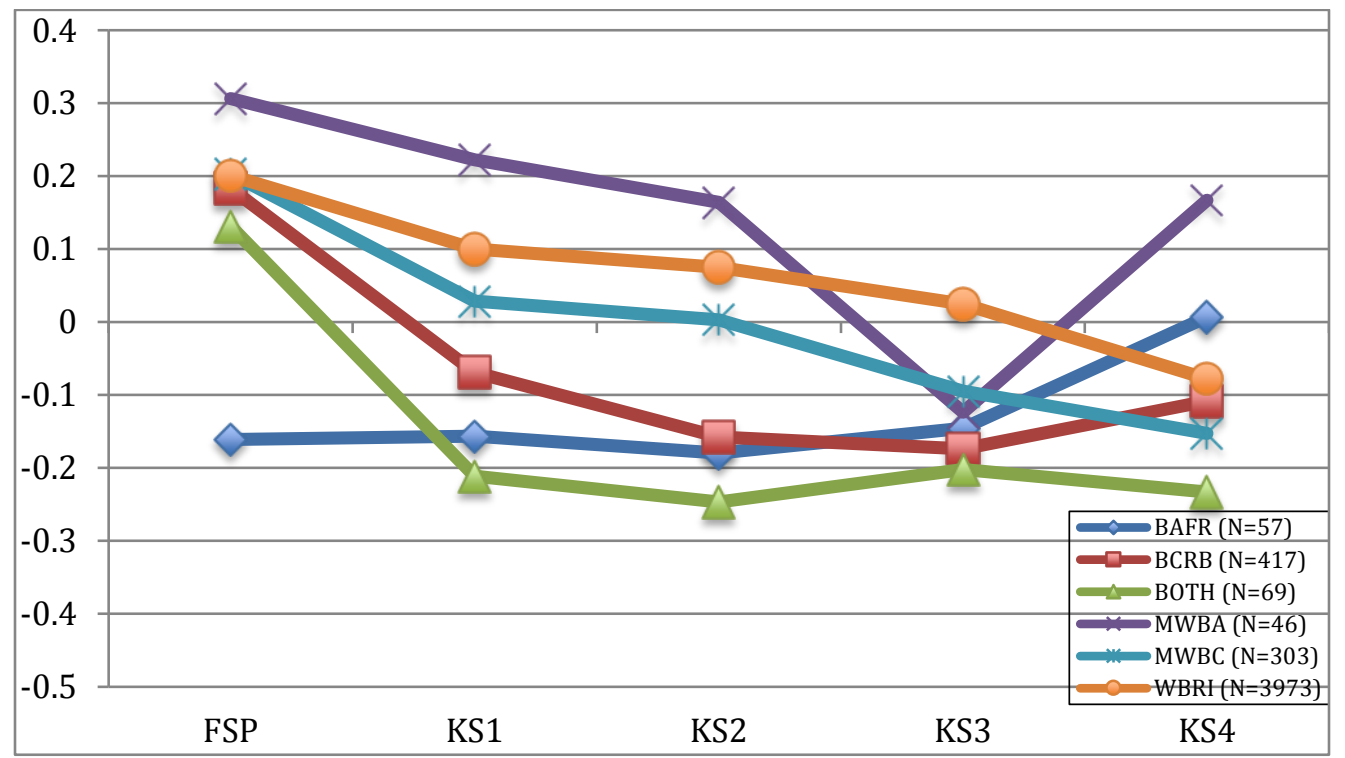

Figure 6. Standardized attainment scores for the Birmingham 2000 cohort for Black and Mixed subgroups

\section{The advantage deriving from being a girl, being non-FSM and being White as compared with Black}

This section begins the examination of the relative influence of gender, deprivation and ethnicity. The advantage of being female reflected in key stage assessments, is depicted in Figure 8. Differences in standardized attainment scores between girls and boys (with positive values indicating higher achievement for girls), fall to the end of KS2 and increase through the secondary stage. The advantage averages about 0.2 of a standard deviation across the assessment points. Figure 8 shows that the advantageous impact of non-FSM increases up to KS3 and then falls but still is at a high level. The average advantage is 0.4 of a standard deviation. 


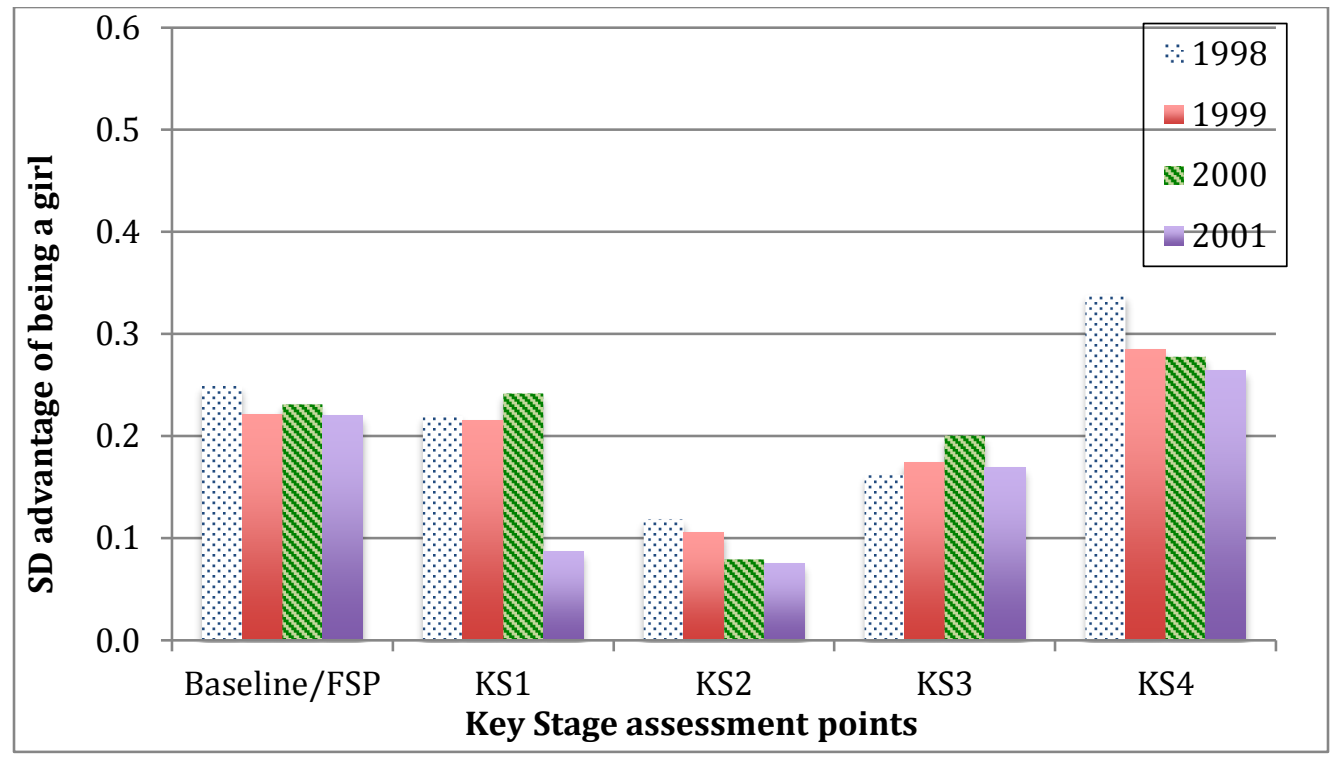

Figure 7. Attainment and gender - standardized score differences from the cohort means at 5 assessment points for the four Birmingham cohorts

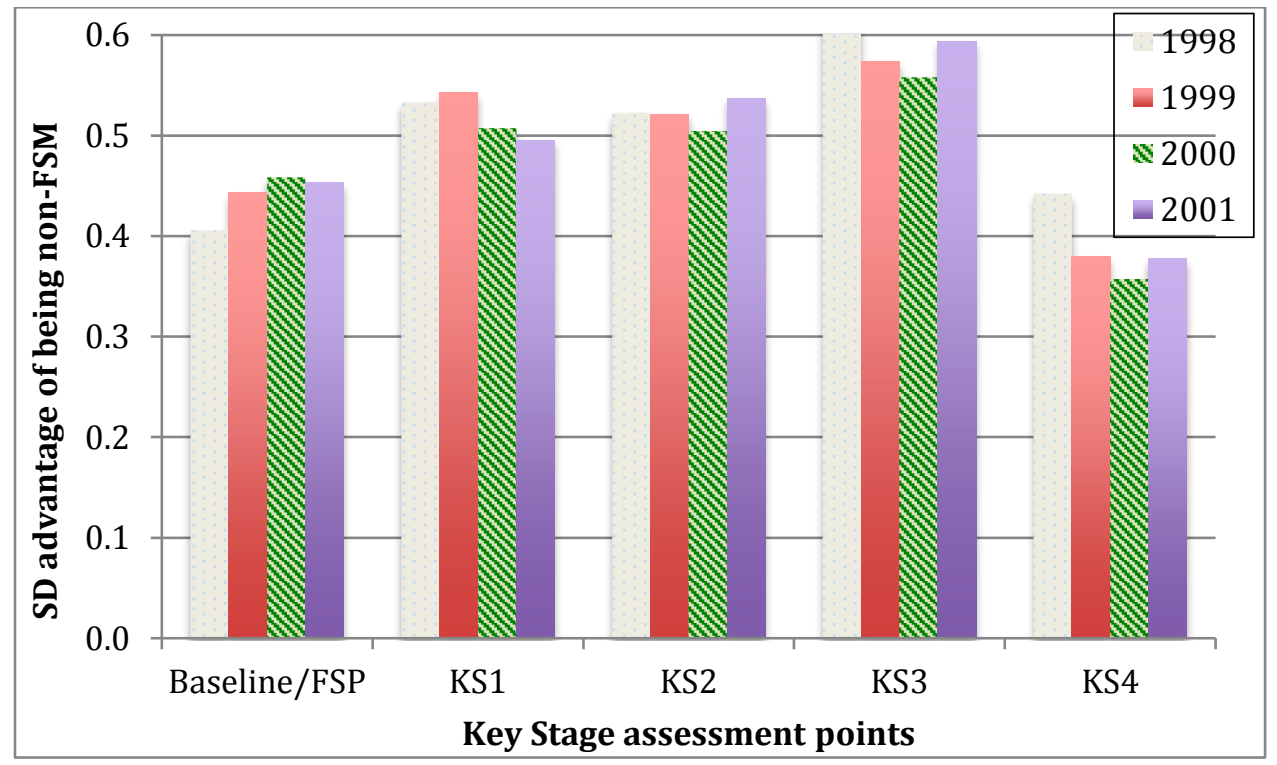

Figure 8. Attainment and FSM - standardized score differences from the cohort means at five assessment points for four cohorts 


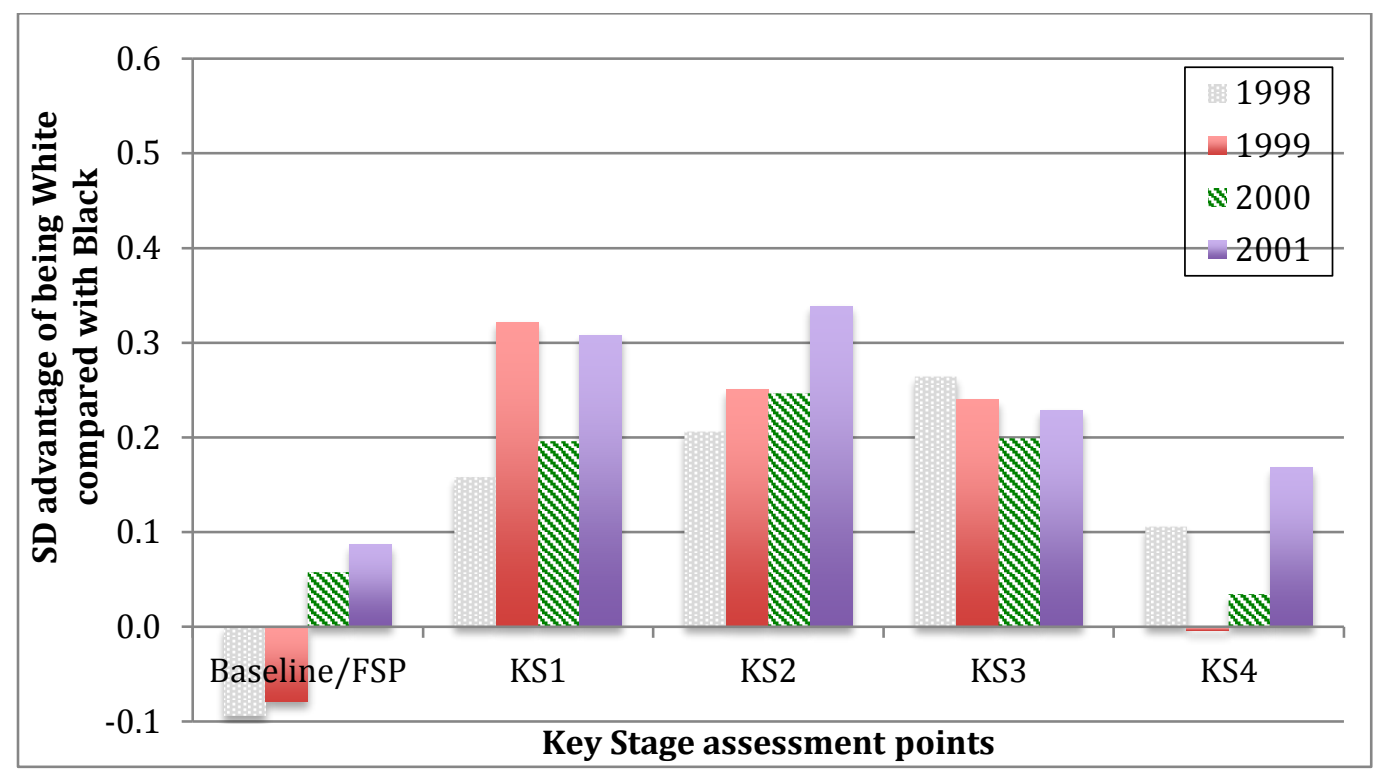

Figure 9. Attainment and Ethnicity - standardized score differences between Black and White pupils at five assessment points for four cohorts

Figure 9 shows the attainment advantage associated with being White compared with Black, which averages less than 0.15 of a standard deviation when calculated across all key stages for all four years. The Baseline measure (1997 to 1999) shows advantage to Black pupils, evident in the minus standard deviation scores registered in these earlier three years. The White advantage is evident for FSP calculated for the later two years (2000 and 2001), as shown in Table 8.

Table 7 also calculates an overall mean across the key stages for the standard deviation difference for gender, deprivation and ethnicity. The overall means indicate the greater advantage stemming from being a non-FSM pupil (0.492) compared with the advantage of being female $(0.195)$ or being White $(0.186)$.

Table 7. Mean standard deviation score differences (advantage) for gender (being female), more affluent (non-FSM) and ethnicity (being White) across four Birmingham cohorts

\begin{tabular}{lcccccc}
\hline & \multicolumn{3}{c}{$\begin{array}{l}\text { Mean key stage score differences } \\
\text { from cohort means }\end{array}$} & $\begin{array}{c}\text { Overall mean } \\
\text { advantage }\end{array}$ \\
\hline & $\begin{array}{c}\text { Baseline/ } \\
\text { FSP }\end{array}$ & KS1 & KS2 & KS3 & KS4 & \\
\hline Attributes & 0.230 & 0.191 & 0.095 & 0.176 & 0.291 & 0.197 \\
\hline Gender (being female) & 0.440 & 0.520 & 0.521 & 0.595 & 0.389 & 0.493 \\
\hline Deprivation (being non-FSM) & & & & & & \\
\hline $\begin{array}{l}\text { Ethnicity 1 (being White. All } \\
\text { 4 years) }\end{array}$ & -0.007 & 0.246 & 0.260 & 0.233 & 0.076 & 0.162 \\
\hline $\begin{array}{l}\text { Ethnicity 2 (being White. } \\
\text { 2000, 2001 cohorts only) }\end{array}$ & 0.073 & 0.244 & 0.266 & 0.215 & 0.041 & 0.186 \\
\hline
\end{tabular}

Tables 7 and 8 indicate the change in 'advantage' from 1998 - 99 Baseline assessments to the subsequent two years of Foundation Stage Profile measures also evident in Figure 10. The table simply compares those categorised as Black or White and the numbers are given for each cohort. The bottom two rows show the difference that results under the Baseline regime and the FSP measures, and, while the mean for these measures does show a reversal - back to a White advantage - for the other four key stages the mean difference is very little changed. 
Table 8. Mean standard deviation score differences at five assessment points for being White compared with Black across four Birmingham cohorts

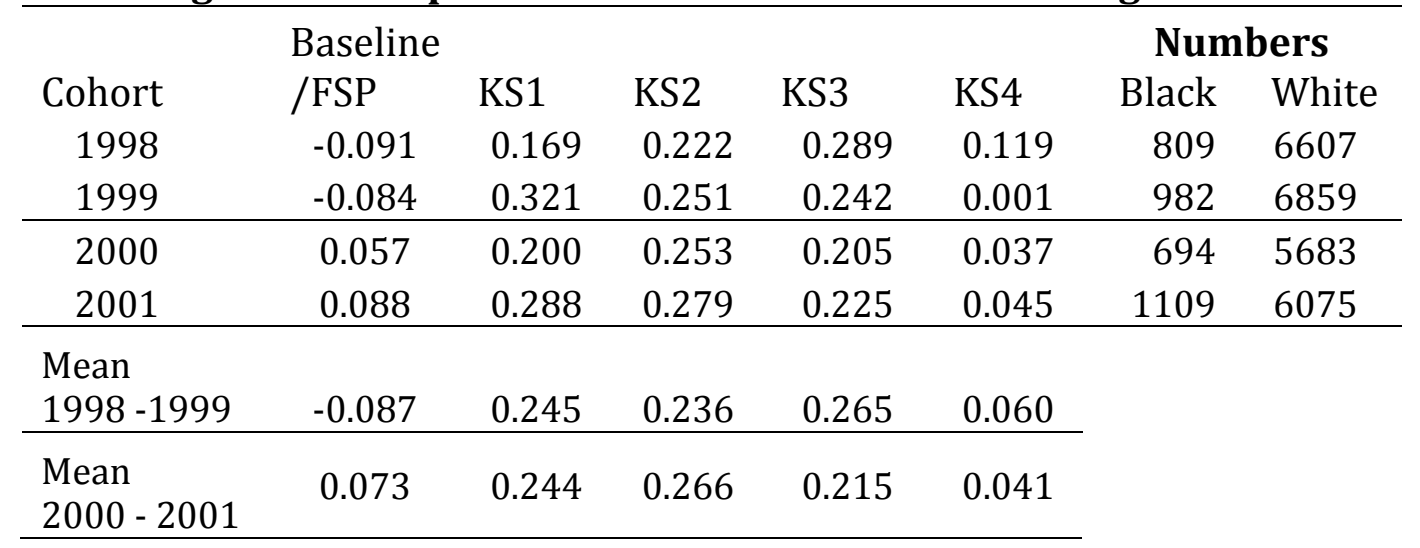

\section{Gender and FSM status differences in attainment within ethnic categories}

Taking the analysis further, we examine how FSM girls perform relative to nonFSM girls, alongside FSM and non-FSM boys and within ethnic categories. We can also see if relative positions change for assessments at different key stage points.

Figures 10 - 12 display assessment data on key stages 1, 2 and 4 for the 2001 cohort (ie born 1995/6 and entered for GCSE/KS4 in 2012). The 2001cohort is depicted here to illustrate the pattern of group differences observable across all four cohorts. The square and diamond markers represent the mean scores for nonFSM pupils and FSM pupils respectively, within gender groups, which are in turn within ethnic categories. The vertical lines show the difference between FSM and non-FSM groups.

In Figure 10, KS1 non-FSM pupils do better (with the exception of BOTH boys and girls - where non-FSM pupils do best), girls do better than boys, and non-FSM Mixed White/Asian girls and boys and Mixed Other girls attain best of all.

It is important to note the relatively small numbers in the Other Black (BOTH=120) and Mixed White/Black African (MWBA=47) categories, smaller still after subdivision into the four subgroups (M/F and FSM/non-FSM) so the variability of the group differences across the three Figures is unsurprising, although the direction of effects is notably consistent. 


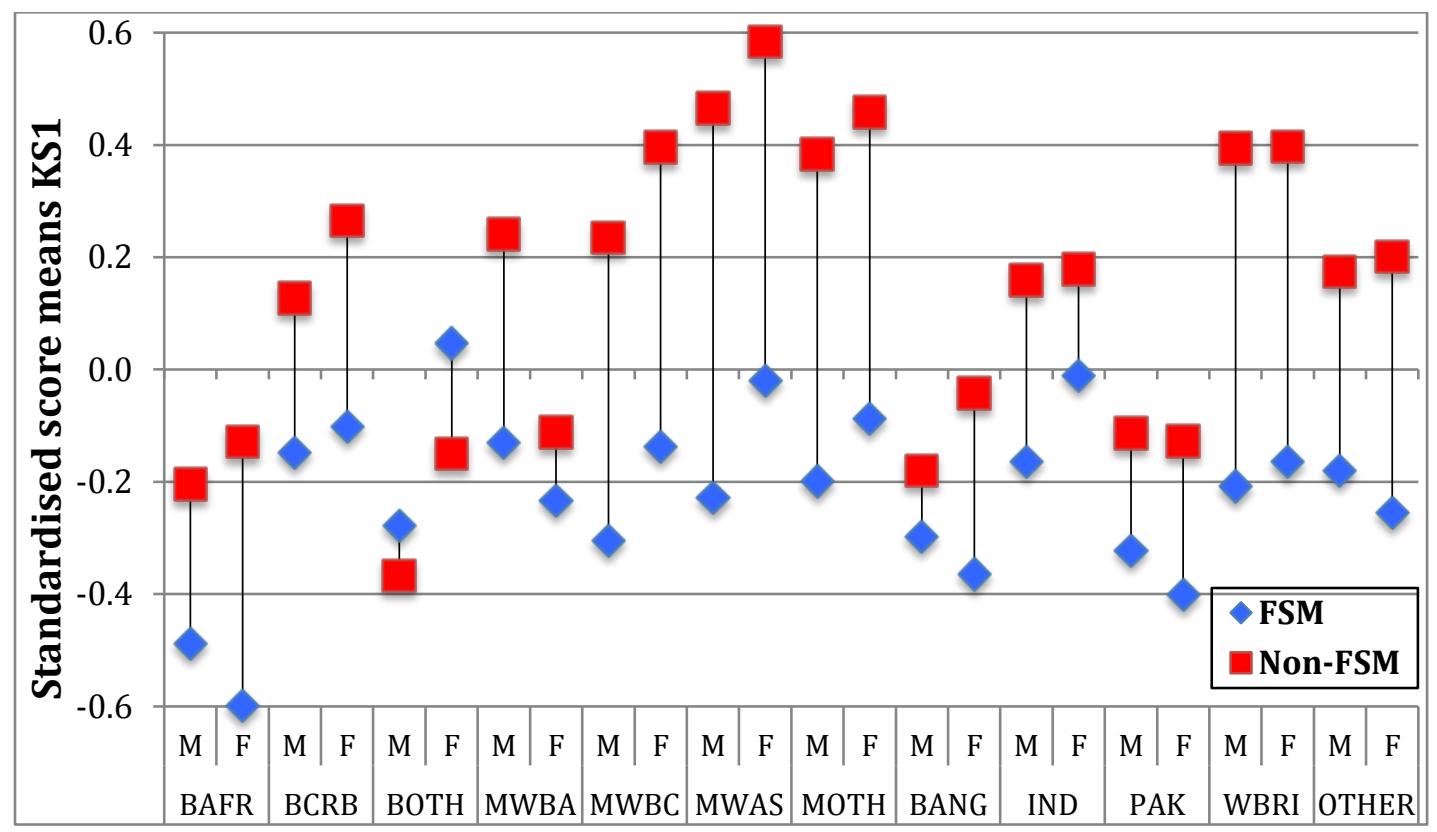

Figure 10. 2001 cohort attainment at KS1 - Standardized score means by FSM/non-FSM within ethnic categories and gender (with vertical gap lines)

Figure 11 shows a fairly similar picture at KS2. Male non-FSM Mixed White/Black African pupils have the highest means, with the non-FSM male Mixed Other group close behind. These are the only two male groups to exceed the scores of their female counterparts. Amongst FSM pupils, Black Caribbean boys, Black Other - both boys and girls - and Mixed White/Black African girls average 0.4 standard deviations below the overall LA average.

The non-FSM groups that achieve below the overall average (the zero line), namely Black Caribbean boys, Black Other boys, Mixed White/Black African girls and Bangladeshi boys. These groups, at this stage (age 11), do not seem to benefit from the protective factor of being relatively 'affluent'.

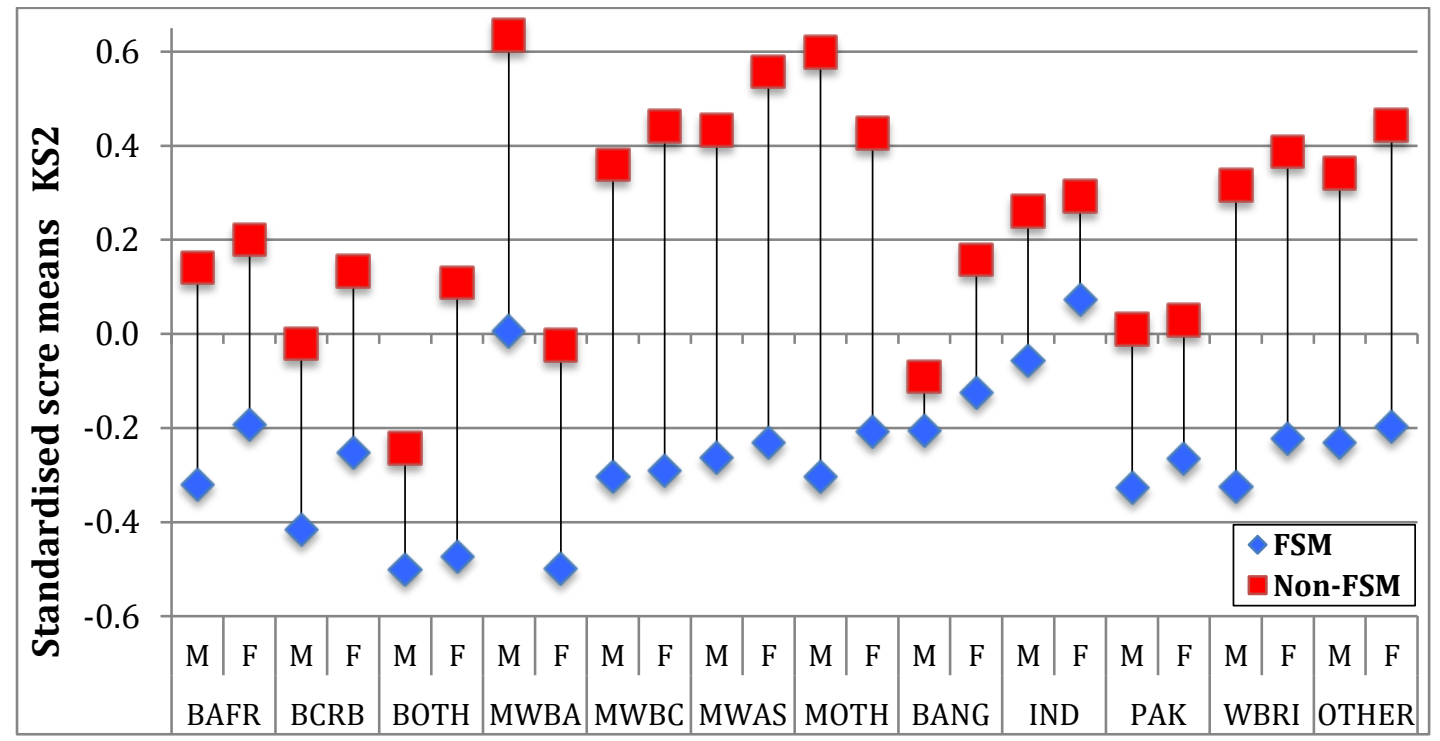

Figure 11. 2001 cohort attainment at KS2 - Standardized score means by FSM/non-FSM within ethnic categories and gender (with vertical gap lines)

Figure 12 shows a rather different pattern at KS4. The difference between boys and girls appears accentuated for the three Asian groups (Bangladeshi, Indian, Pakistani), the White British group, and the Other group. The difference between 
boys and girls for these groups is about a quarter of a standard deviation - to the advantage of girls. The FSM mean attainment levels for almost all boys, recording well below average at KS2, continue at a low level, with the means for Mixed White/Black Caribbean and White FSM boys very much the worst of all. Higher attainers are the non-FSM Mixed White/Black African (both boys and girls), Mixed White/Asian boys, Bangladeshi girls and Indian girls. As noted in other research (Strand, 2011, p. 215), some non-FSM Black boy groups do less well than might be expected. It is instructive too to note the high performing FSM groups: Mixed White/Black African boys, Bangladeshi, Indian and Pakistani girls score above the LA average at KS4.

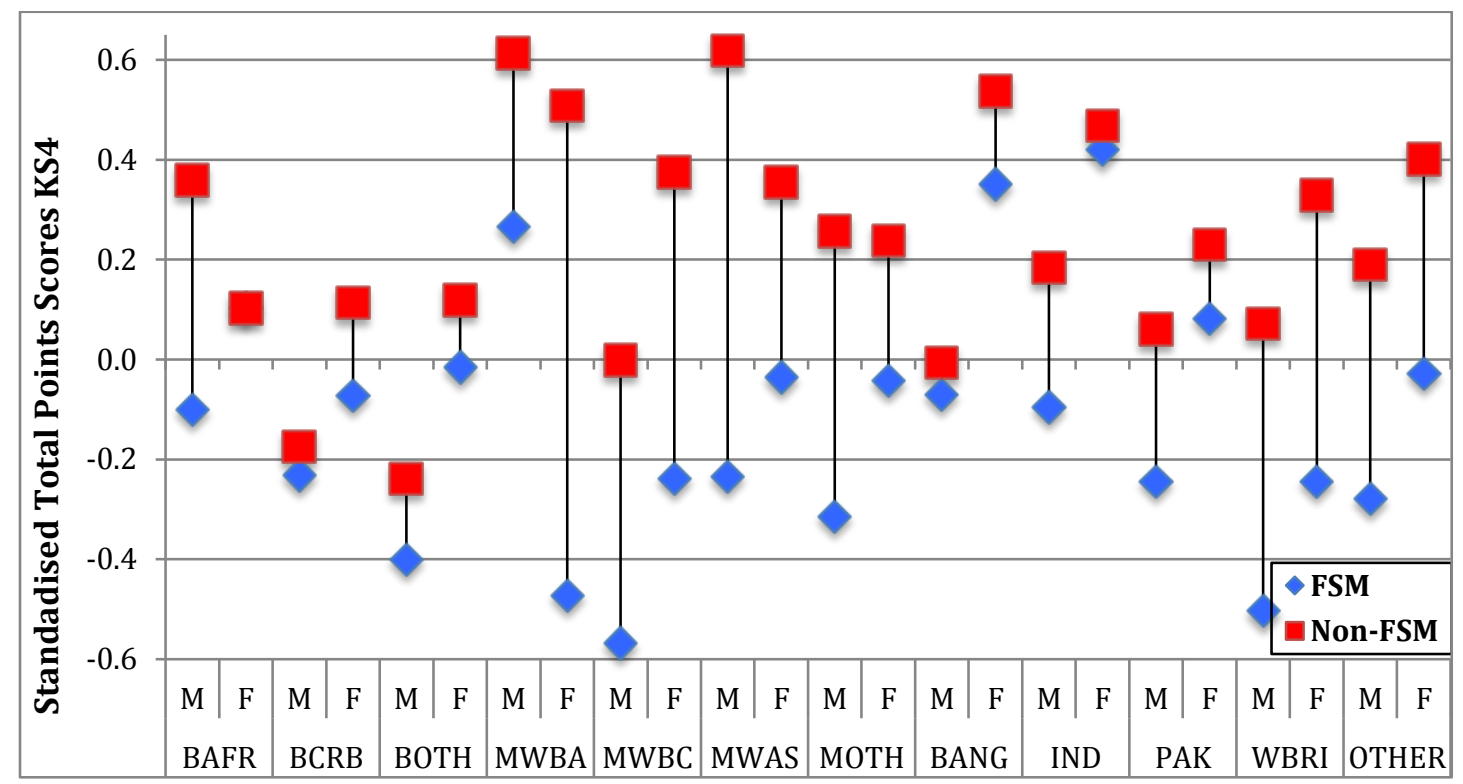

For BAFR female pupils, the FSM and non-FSM scores are identical and only the one plot is visible.

Figure 12. 2001 cohort attainment at KS4 - Standardized score means by FSM/non-FSM within ethnic categories and gender (with vertical gap lines)

Analysis by gender and deprivation sub-groups within ethnic groups in Figures 10 - 12 in this section show some sub-groups' low attainment levels are maintained or worsen from KS2 to KS4; leaving aside the BAFR, BOTH and MWBA pupils, where the total numbers are under 100, Mixed White/Black Caribbean FSM boys and White British FSM boys are confirmed as the lowest attainers at 16. Of the FSM girls in these larger groups, it is the Mixed White/Black Caribbean and White British that fare least well. In line with national statistics (Table 1), non-FSM Black Caribbean, and Mixed White/Black Caribbean boys do noticeably less well than non-FSM White British boys.

\section{Using multiple regression procedures, the relative effect of ethnicity, gender, deprivation, SEN and age on attainment at different key stage levels}

This last section applies multiple regression (Cohen et al. 2003; Pallant 2010) to the full set of Birmingham school population data. A selection of the results is given below. The aim of this analysis is to:

(i) ascertain whether the differences between groups observed in the figures reach statistical significance;

(ii) compute an estimate of comparative effect sizes of each factor;

(iii) evaluate the degree to which variation in overall attainment can be accounted for by ethnic group, gender and deprivation; 
(iv) determine whether differences between ethnic groups in attainment are still apparent after controlling for differences in FSM, IDACI etc.

A fixed effect multiple regression was used in preference to modelling ethnicity as a random effect in a multilevel model. We did this as the conclusions we wished to show regarding ethnicity are largely confined to those included in the population cohorts under study and we also wished to make comparisons between specific ethnic groups (as opposed to simply assessing the general overall impact of ethnicity); these are conditions under which fixed effects models may be more appropriate (Littell, Stroup and Freund 2002). A two-stage hierarchical regression was used with (1) contextual variables of age, FSM, IDACI Score, SEN and Gender entered in block 1 to examine their relative contributions to attainment and 2) ethnicity entered into block 2 so that the impact of ethnicity on attainment after controlling for these variables could be examined. Given the multiple groups that comprised the ethnicity variable, dummy coding was used (Cohen et al. 2003) with White chosen as a comparative reference group (the total contribution of ethnicity as a whole to attainment is not affected by choice of reference group, but a reference group must be specified within the dummy coding system). A positive regression coefficient (B) indicates a higher score for the specified group relative to Whites (Hierarchical regression was used with ethnicity entered in Block 2, and other contextual variables (Date of Birth, IDACI Rank, FSM, SEN and Gender) entered in Block 1, to see if ethnicity accounted for attainment above and beyond the influence of these variables (Cohen et al. 2003).

Table 9. Multiple regression analysis on 2001 Cohort Foundation Stage

\begin{tabular}{|c|c|c|c|c|c|}
\hline & & \multicolumn{4}{|c|}{ Standardized Coefficients } \\
\hline & & $\mathrm{B}$ & Sig & $\mathrm{B}$ & Sig \\
\hline & (Constant) & 90.214 & $<.001^{* * *}$ & 90.121 & $<.001^{* * *}$ \\
\hline \multirow[t]{5}{*}{ Model 1} & DoB & -0.003 & $<.001^{* * *}$ & -0.003 & $<.001^{* * *}$ \\
\hline & IDACIRank & 0 & $<.001^{* * *}$ & 0 & $<.001^{* * *}$ \\
\hline & FSM1Y2N & 0.257 & $<.001^{* * *}$ & 0.232 & $<.001^{* * *}$ \\
\hline & SEN1Y2N & 0.529 & $<.001^{* * *}$ & 0.527 & $<.001^{* * *}$ \\
\hline & GENM1F2 & 0.183 & $<.001^{* * *}$ & 0.184 & $<.001^{* * *}$ \\
\hline \multirow[t]{11}{*}{ Model 2} & vBAFR & & & -0.352 & $<.001^{* * *}$ \\
\hline & vBANG & & & -0.433 & $<.001^{* * *}$ \\
\hline & vBCRB & & & 0.109 & $.004^{* *}$ \\
\hline & vBOTH & & & 0.242 & $.005^{* *}$ \\
\hline & vIND & & & -0.153 & $<.001^{* * *}$ \\
\hline & vMOTH & & & 0.138 & $.028 *$ \\
\hline & vMWAS & & & -0.065 & .405 \\
\hline & vMWBA & & & 0.018 & .894 \\
\hline & vMWBC & & & 0.197 & $<.001^{* * *}$ \\
\hline & vPAK & & & -0.468 & $<.001^{* * *}$ \\
\hline & vOTHER & & & -0.105 & $.002^{* *}$ \\
\hline $\mathbf{R}^{2}$ & & 20.9 & & 25.3 & \\
\hline
\end{tabular}

Statistical significance: ${ }^{*}$ at $5 \%(0.05) ;{ }^{* *}$ at $1 \%(0.01) ;{ }^{* * *}$ at $0.01 \%(0.001)$

Results of the regression are presented in Tables 9 and 10 for the most recent cohort (2001), at the Foundation Stage and Key Stage 4. A positive regression coefficient (B) indicates a higher score for the specified group relative to the White reference group. A careful examination of Table 9 shows five ethnicities being 
highly significant (greater than 1\% level) in their negative association with low attainment at the Foundation Stage: Black African, Bangladeshi, Indian, Mixed White/Asian, and Pakistani. This is after the Model 1 variables have been taken into account. Language is clearly a factor at this early stage. In Table 10, none of the ethnicities is negatively associated with low attainment, again after Model 1 variables have been entered. In relation to the impact of FSM status, it should be noted that FSM rates in Birmingham are twice the national average and six of the identified ethnic groups have FSM rates of over 50\% (DfE 2013, Local Authority and Regional, Tables 8a-c).

Table 10. Multiple regression analysis on 2001 Cohort KS4

\begin{tabular}{|c|c|c|c|c|c|}
\hline & & \multicolumn{3}{|c|}{ Standardized Coefficients } & \multirow[b]{2}{*}{ Sig } \\
\hline & & B & Sig & B & \\
\hline \multirow[t]{6}{*}{ Model 1} & (Constant) & 4.126 & .207 & 3.759 & .247 \\
\hline & DoB & 0 & .083 & 0 & .098 \\
\hline & IDACIRank & -0.544 & $<.001^{* * *}$ & -0.716 & $<.001^{* * *}$ \\
\hline & FSM1Y2N & 0.230 & $.022^{*}$ & 0.245 & $<.001^{* * *}$ \\
\hline & SEN1Y2N & 0.590 & $.026^{*}$ & 0.589 & $<.001^{* * *}$ \\
\hline & GENM1F2 & 0.221 & $.020^{*}$ & 0.222 & $<.001^{* * *}$ \\
\hline \multirow[t]{11}{*}{ Model 2} & vBAFR & & & 0.278 & $<.001^{* * *}$ \\
\hline & vBANG & & & 0.417 & $<.001^{* * *}$ \\
\hline & vBCRB & & & 0.054 & .223 \\
\hline & vBOTH & & & 0.056 & .576 \\
\hline & vIND & & & 0.263 & $<.001^{* * *}$ \\
\hline & vMOTH & & & 0.094 & .199 \\
\hline & vMWAS & & & 0.284 & $.002^{*}$ \\
\hline & vMWBA & & & 0.417 & $.009^{*}$ \\
\hline & vMWBC & & & 0.012 & .835 \\
\hline & vPAK & & & 0.215 & $<.001^{* * *}$ \\
\hline & vOTHER & & & 0.182 & $<.001^{* * *}$ \\
\hline $\mathbf{R}^{2}$ & & $1.1 \%$ & & $12.6 \%$ & \\
\hline
\end{tabular}

Statistical significance: ${ }^{*}$ at $5 \%(0.05) ;{ }^{* *}$ at $1 \%(0.01) ;{ }^{* * *}$ at $0.01 \%(0.001)$

The $\mathrm{R}^{2}$ statistic is the best indicator of the combined explanatory strength of the variables entered. At the Foundation Stage, Model 1 explains $20.9 \%$ of the variance in attainment, which is increased by $4.4 \%$ by the inclusion of the ethnicity variables. At KS4, Model 1 explains only $11.1 \%$ of the variance in attainment across the entire cohort, raised by $1.5 \%$ by the ethnicity variables in Model 2. 
Table 11. Model Summaries for 2001 Cohort at 5 assessment points

\begin{tabular}{cccc}
\hline \multicolumn{2}{l}{ Dependent } & & \multicolumn{2}{l}{ R Square } \\
Variable & Model & R Square & Change \\
\hline FSP & Model 1 & $0.209^{* *}$ & \\
& Model 2 & $0.253^{* *}$ & $4.4^{* *}$ \\
\hline \multirow{2}{*}{ KS1 } & Model 1 & $0.161^{* *}$ & \\
& Model 2 & $0.171^{* *}$ & $1.1^{* *}$ \\
\hline \multirow{2}{*}{ KS2 } & Model 1 & $0.237^{* *}$ & \\
& Model 2 & $0.240^{* *}$ & $0.3^{* *}$ \\
\hline \multirow{2}{*}{ KS3 } & Model 1 & $0.283^{* *}$ & \\
& Model 2 & $0.286^{* *}$ & $0.3^{* *}$ \\
\hline \multirow{2}{*}{ KS4 } & Model 1 & $0.112^{* *}$ & \\
& Model 2 & $0.126^{* *}$ & $1.5^{* *}$ \\
\hline
\end{tabular}

Model 1: (Constant), GENM1F2, FSM1Y2N, DoB, SEN1Y2N, IDACIRank

Model 2: (Constant), GENM1F2, FSM1Y2N, DoB, SEN1Y2N, IDACIRank, vMWBA, vMWAS, vBOTH, vMWBC, vMOTH, vBCRB, vOTHER, vBAFR, vIND, vBANG, vPAK

This same analysis was carried out for all five assessment points for the 2001 cohort and the results are set out in Table 11 . These suggest that ethnicity is most influential at the FSP stage, consistent with earlier figures. The best that can be explained by Model 1 is 28\% (KS3) and the best that the addition of the ethnicity variables contributes is $4.4 \%$ (FSP stage).

Table 12 is a compressed presentation of the addition brought about by Model 2 at each assessment point. It emphasises that the ethnicity variable is most powerful at the Baseline/FSP assessment point. At KS1, 2 and 3 the percentage contribution is very small, rising a little at KS4.

Table 12. Change in $R^{2}$ with addition of ethnicity

\begin{tabular}{lcccc}
\hline $\begin{array}{l}\text { Assessment } \\
\text { stage }\end{array}$ & $\mathbf{4}$ & Cohort \\
\hline Baseline/FSP & $3.4 \%$ & $3.2 \%$ & $4.4 \%$ & $5.3 \%$ \\
KS1 & $1.3 \%$ & $1.2 \%$ & $1.1 \%$ & $0.4 \%$ \\
KS2 & $0.4 \%$ & $0.4 \%$ & $0.7 \%$ & $0.3 \%$ \\
KS3 & $0.7 \%$ & $1.0 \%$ & $1.0 \%$ & $1.0 \%$ \\
KS4 & $1.5 \%$ & $1.4 \%$ & $2.0 \%$ & $2.2 \%$ \\
\hline
\end{tabular}

The percentage change figures for 2001 are given in Table 11

These data point conclusively to the greatest influence, from the variables we have, stemming from economic and social disadvantage as indicated by FSM eligibility and Income Deprivation score.

\section{Conclusion: theoretical perspectives, causal factors and inequity in educational attainment}

Economic disadvantage is a more powerful correlate with low attainment than gender or ethnicity. Table 7 indicates .49 of a standard deviation advantage associated with being non-FSM, .20 for being female and .19 for being White. The multiple regression analysis puts the influence of ethnicity as low as $1.5 \%$ at KS4 (Table 11).

Racism exists within British society and operates within most public and private services and enterprises, however implicitly. The same can be said of sexism. The evidence is in the unequal outcomes in employment, income, housing, longevity 
and life chances (EHRC 2016). There are also the recurrent deficient outcomes for children from less affluent backgrounds in education, health and the criminal justice system.

There are three key requirements for our thinking in the current era in relation to ethnicity, educational attainment and equity. Firstly, the need to recognise that some minorities perform well in education - Asian heritage, Black African - and others year on year do not - Black Caribbean, Black other and Mixed White/Black Caribbean.

Secondly, the relative inequities change over the course of children's school careers. The Birmingham data show Bangladeshi and Pakistani pupils approaching national average scores as they go through the key stages, the former exceeding the national average at KS4 (Figures 1 - 4). Correspondingly, we see the average scores for White pupils declining relative to the LA norm from Foundation/Baseline through to KS4, and the average for Black (or for Black Caribbean) pupils declining until KS3 and then rising (e.g. Figures 5 and 7).

Thirdly, the relative performance of ethnic minority pupils has changed in the last decade and earlier stark inequalities no longer apply in the same way or to the same degree in 20144. The gap between Mixed White/Black Caribbean and White and between Black Caribbean and White pupils practically halved for both boys and girls. The mean for Black African pupils, a group that has increased greatly in number over the period, exceeds that for White pupils in 2014 (DCSF 2007, p4 for 2006 figures; DfE 2015b for 2014 figures). Thus, there is reason to believe that the huge inputs in multicultural education and the volume of National Strategies publications have had an impact (DfES 2003, 2004; DCSF 2007, 2008, 2009). This stimulus has ceased since 2010.

Neither notions of institutional racism or precepts of Critical Race Theory (CRT) offer sound and practical explanations of the low average attainment of some ethnic minority groups (Gillborn 2005, 2006a). Phillips (2011) makes telling criticisms of the term 'institutional racism', in particular 'the absence of a clear theoretical basis for specifying the mechanisms through which institutional rather than individual racism operated to disadvantage certain groups'. (Phillips 2011: 273 , original emphasis) ${ }^{5}$. Critical Race Theory (CRT) is similarly short on theory and references to 'intersectionality' are confined to qualitative data. What CRT lacks is a structural dimension which seeks to bridge agency and social structure: why people think and behave as they do and the extent to which this is determined by their socio-economic context. Gillborn used Birmingham data to provide the basis for aspects of his theorising showing that the change from baseline assessment at age 5 to FSP from 2000 onward reduced Black children's mean score so that they no longer outperformed White pupils'. Gillborn labels this as 'worse than a conspiracy' against the population of Black learners (Gillborn, 2008a, p. 241) and elsewhere refers to 'White supremacy'7 (Gillborn 2005: 485) and the 'undeclared war on Black children' (Gillborn 2013: 477). Parsons (2017) examines the weaknesses and possible loss of association with policy solutions that CRT represents.

Marxists (Cole 2016; Hill 2009; Maisuria 2012;) have claimed that CRT does not acknowledge the conflicting roles of finance and labour and fails to link 'the subjective micro with the objective macro' (Maisuria 2012: 87). Cole draws attention to the UK's contemporary 'multifaceted forms of colour-coded, noncolour-coded and hybridist racism .... racism directed at Eastern European migrant 
workers and their families: xeno-racism' (Cole 2016: 27/8). Sivanandan, in the interestingly titled Poverty is the new Black, posits racism as a cultural phenomenon, susceptible to cultural solutions (eg multicultural education), but related to economic inequality. His view is that 'Racism needs to be tackled at both levels - the cultural and the economic - at once, remembering that the one provides the rationale for the other' (Sivanandan 2001: 1). Racism and inequality both need to be tackled within a multi-level framework as Phillips proposes, indeed, an ecological framework where we recognise concentric circles of advantage and obstruction from the micro to the macro. This is what Raffo et al (2010) propose in their focus on Area Based Initiatives where they note that so many solutions fail to fully recognise numerous factors external to the school' (Raffo et al. 2010: 189). Tucker sets out a set of 'key Elements of a life chances strategy' which contains eight elements; only two of these concern education or children's services (Tucker 2016). Marmot's impressive work on social determinants of health lists factors which apply equally to what makes for success in education. He ventures into education and reminds us that, as well as the need for good schools, 'To achieve good educational results, we need to reduce poverty and socio-economic inequality and to improve the family and community context in which children's education takes place' (Marmot 2015:169).

We argue from a structuralist and ecological perspective, focussing on the distribution of power in society, inequalities of wealth and income and the creation and maintenance of poor communities. Where there is political will, positive action targeted at key points in school careers, it is likely to have some equalising effect. Birmingham data demonstrate the local complexity, change in the short-term and local political forces played out in a national scene.

At the national level, data assembled by OECD (2014) and UNICEF (2012) show that most other European countries do not suffer inequalities of wealth and income to the same degree as the UK. Under-performance in educational outcomes is strongly related to measures of deprivation at every level of assessment, including university. Sadly, senior education professionals, directors of education and children's services and head teachers are largely seduced into thinking that schools can do the major part of correcting life chance inequalities.

\section{Acknowledgement}

We thank the Birmingham Assessment Unit and the Children, Young People and Families Information Management Team who provided the data for five cohorts matched across key stage assessment points. This was a large, unique body of data with which we were privileged to work. Without the work of the Birmingham teams, this analysis would not have been possible and attempts at understanding the complexities of the education system would have been harder.

We would like to thank Stephen Steadman for his critical inputs to the development of this paper. Ray Godfrey was part of the original formulation of the project at Canterbury Christ Church University and has advised on analytical approaches. Gill Fairbanks and David Ewens were fierce in demanding clarity and syntactical propriety; we tried hard to meet their high standards. 


\section{References}

Cohen, J., P. Cohen, S. West, and L. Aiken. 2003. Applied multiple regression/correlation analysis for the behavioral sciences (3rd ed.). Mahwah, NJ: Lawrence Erlbaum Associates.

Cole, M. 2009. Critical Race Theory and Education: A Marxist Response. Basingstoke: Palgrave MacMillan.

Cole, M. 2015. Racism: a Critical Analysis. London, Pluto Press

DCSF 2007. Ensuring the Attainment of Black Pupils (The National Strategies: Secondary). Nottingham: DCSF Publications.

DCSF 2008. Excellence and Enjoyment: learning and teaching for Black children in the primary years (The National Strategies: Primary). Nottingham: DCSF Publications.

DCSF 2009. Narrowing the Gaps - Resources to support the achievement of Black and minority ethnic, disadvantaged and gifted and talented pupils (The National Strategies: Secondary). Nottingham: DCSF Publications.

DfES 2003. Aiming High: Raising the Achievement of Minority Ethnic Pupils. London: Department for Education and Skills.

DfES 2004. Aiming High: Supporting Effective Use of EMAG. London: Department for Education and Skills.

DfE 2013. Schools, pupils and their characteristics: January 2015. London: Department for Education. https://www.gov.uk/government/statistics/schools-pupils-and-theircharacteristics-january-2013

DfE 2015a. Early years foundation stage profile results: 2014 to 2015. London: Department for Education. https://www.gov.uk/government/statistics/earlyyears-foundation-stage-profile-results-2014-to-2015

DfE 2015b. GCSE and equivalent attainment by pupil characteristics SFR05/2015. London: Department for Education.

https://www.gov.uk/government/statistics/gcse-and-equivalent-attainmentby-pupil-characteristics-2014

DfE 2016. Revised GCSE and equivalent results in England: 2014 to 2015. London: Department for Education.

https://www.gov.uk/government/statistics/revised-gcse-and-equivalentresults-in-england-2014-to-2015

EHRC 2012a. Technical Guidance for Schools in England. London: Equality and Human Rights Commission.

http://www.equalityhumanrights.com/uploaded files/EqualityAct/PSED/tech nical guidance schools england final.pdf (accessed 25 November, 2013).

EHRC 2012b. Public Sector Equality Duty Guidance for Schools in England. London: Equality and Human Rights Commission. http://www.equalityhumanrights.com/uploaded files/EqualityAct/PSED/publi c sector equality duty guidance for schools in england final.pdf

EHRC 2016. Healing a Divided Britain: the need for a comprehensive race equality strategy. London: Equality and Human Rights Commission. https://www.equalityhumanrights.com/sites/default/files/healing_a_divided_ britain_-_the_need_for_a_comprehensive_race_equality_strategy_final.pdf

Gillborn, D. 2005. Education policy as an act of White supremacy: Whiteness, critical race theory and education reform. Journal of Education Policy. 20: 485505. 
Gillborn, D. 2006a. Citizenship education as placebo: 'standards', institutional racism and educational policy. Education, Citizenship and Social Justice. 1: 83104.

Gillborn, D. 2006b. Rethinking White Supremacy: Who Counts in 'White World'. Ethnicities. 6: 318-340.

Gillborn, D. 2008a Racism and Education: Coincidence or Conspiracy. London: Routledge.

Gillborn, D. 2008b. Coincidence or conspiracy? Whiteness policy and the persistence of the White achievement gap, Educational Review. 60: 229-248.

Gillborn, D. 2013. Interest-divergence and the colour of cutbacks: race, recession and the undeclared war on Black children. Discourse: Studies in the Cultural Politics of Education, 34: 477-491.

Gillborn, D. and H. S. Mirza. 2000. Educational Inequality: Mapping Race, Class and Gender - a Synthesis of Research Evidence. London: OFSTED.

Hill, D. 2009. Race and Class in Britain: a critique of the statistical basis for Critical Race Theory in Britain: and some political implications. Journal for Critical Education Policy Studies, 7: 1-40.

H M Government 2010. Equality Act 2010 (London, The Stationery Office).

Littell, R. C., W. W. Stroup, and R. J. Freund. 2002. SAS for Linear Models. SAS Institute Inc.: Cary, NC.

Maisuria, A. 2012. A critical appraisal of critical race theory (CRT): limitations and opportunities. In K. Bhopal and J. Preston. Intersectionality and "Race" in Education. Abingdon: Routledge.

Marmot, M. 2015. The health gap: the challenge of an unequal world. London: Bloomsbury.

OECD 2014. Income Inequality Update: rising inequality: youth and poor fall further behind. Paris: Organisation for Economic and Cultural Development. www.oecd.org/social/inequality-and-poverty.htm

Pallant, J. 2010. SPSS Survival Manual: a step by step guide to data analysis using SPSS. Maidenhead: Open University Press.

Parsons, C. 2016. The role of ethnicity, gender, deprivation and low attainment in England - political arithmetic, ideological stances and the deficient society. Education, Citizenship and Social Justice, 11: 160-183.

Parsons, C. 2017. (forthcoming) Critical race theory: a cautionary note.

Phillips, C. 2011. Institutional Racism and ethnic inequalities: an expanded multilevel framework. Journal of Social Policy, 40:173-192

Raffo, C., A. Dyson, H. Gunter, D. Hall, L. Jones and A. Kalamouka. 2010.Poverty and educational policy initiatives. In Education and Poverty in Affluent Countries, edited by C. Raffo, A. Dyson, H. Gunter, D. Hall, L. Jones and A. Kalamouka. London: Routledge.

Savanandan, A. 2001. Poverty is the new Black. Race and Class 43: 1-5.

Strand, S. 2011. The limits of social class in explaining ethnic gaps in educational attainment. British Educational Research Journal, 37: 197-229.

Taylor, E., D. Gillborn, and G. Ladson-Billings. 2009. Foundations of critical race theory. London: Routledge.

Tucker, J. 2016. Improving children's life chances. London: Child Poverty Action Group.

UNICEF 2012. Measuring Child Poverty, Report Card 10. Florence, Innocenti Research Centre. 
Warren, S. and D. Gillborn. 2003. Race Equality and Education in Birmingham. Birmingham: Birmingham City Council and Birmingham Race Action Partnership.

\footnotetext{
${ }^{1}$ Birmingham supplied five cohorts but the 1997 cohort was omitted as we considered four to be a sufficient set of repeated measures for the case to be made about constancy and change.

${ }^{2}$ Chinese pupils, of whom there are few, achieve even higher levels especially at KS3 and KS4.

${ }^{3}$ Changes across time for a group can only really be used to suggest an increase/decrease relative to the other groups. Because scores were necessarily standardized to make the different assessments numerically comparable, it is impossible to assess whether scores were actually going up or down across time in an absolute sense.

${ }^{4}$ The exception is the enduring and shocking disparity with Irish Traveller and Gypsy/Roma children, continuing high on exclusions and very low on attainment.

5 'Institutional racism', so central to the Macpherson report on the murder of Stephen Lawrence, is not a term that appears in two landmark equalities Acts of Parliament - Race Relations

(Amendment) Act 2000 or the Equality Act 2010. It is likely that legal advice was that the term was too imprecise to bring casesof compliance or breach.

${ }^{6}$ The Baseline protocol rested heavily on a combination of parental judgement and early teacher assessment at the start of schooling and was a 'snapshot'; the FSP protocol guided teachers' judgement on a range of criteria over a longer period. The analysis (Figures $1-6$ and 9 and Table 7) show that these changes have not been great and have not affected trajectories of attainment during later stages of schooling.
}

${ }^{7}$ Cole makes the point that 'such language as a descriptor of everyday racism is useless as unifier and counter-productive as a political rallying point' (Cole 2015: 20). Though flawed theorectically, CRT may well serve these social and quasi-political purposes. 